\section{Entrevista a \\ Marcelo El \\ Khouri Buzato}

Mônica Ferreira Mayrink

Lívia Márcia Tiba Rádis Baptista
Marcelo El Khouri Buzato

Doutor em Linguística Aplicada pela UNICAMP (2007) com estágio pósdoutoral realizado na Universidade da Califórnia (2015). Docente do Programa de Pós Graduação em Linguística Aplicada da UNICAMP, atua na área de Linguagem e Sociedade, na linha de pesquisa em Linguagens e Tecnologias. Organizou os volumes "Cultura Digital e Linguística Aplicada" (Pontes, 2016) e "New Literacies, New Agencies?" (Peter Lang, 2013).

Contato: mbuzato@iel.unicamp.br

Mônica Ferreira Mayrink

Doutora e Mestre em Lingüística Aplicada e Estudos da Linguagem pela Pontifícia Universidade Católica de São Paulo. Professora da Graduação e Pós-Graduação no Departamento de Letras Modernas da Faculdade de Filosofia, Letras e Ciências Humanas da USP. Tem experiência na área de Linguística Aplicada, com ênfase nos seguintes temas: formação de professores, reflexão, ensino e aprendizagem de línguas presencial e a distância.

Contato: momayrink@usp.br

Lívia Márcia Tiba Rádis Baptista

Doutora em Linguística pela UNICAMP e Mestre em Letras e em Educação, ambos pela Universidade de São Paulo. Professora do Departamento de Letras Românicas da Universidade Federal da Bahia. Atua nos programas de Pós-Graduação em Linguística da UFC e no de Pós-Graduação em Língua e Cultura da LIFBA. Tem experiência na área de Linguística Aplicada, principalmente nos seguintes temas: ensino e aprendizagem de línguas e formação de professores.

Contato: liviarad@yahoo.com

Aceito em: 14 de dezembro de 2016 
CARACOL: Muito se fala sobre o impacto das tecnologias no ensino na atualidade. Como você caracteriza esse cenário?

Marcelo El Khouri Buzato: Primeiro me permita ressalvar, eu considero a metáfora do "impacto" inadequada. Qualquer tecnologia é um tecido orgânico de princípios científicos, soluções técnicas e forças sociais e políticas, ou seja, elas não são, como muitos querem, algo externo às relaçóes entre grupos sociais, às ideologias e aos conflitos sociais, mas surgem justamente nessa rede de relações. Talvez por isso mesmo tenha ficado cada vez mais claro que não há impacto educacional do computador, não se trata de trazer uma solução técnica vinda de outro lugar, talvez outro planeta (risos) e jogar no contexto educacional.

Contudo, certamente a educação não é totalmente refratária ao conjunto de transformaçôes sociais, políticas e epistêmicas que vem se instalando paulatinamente desde que os computadores e as redes telemáticas tornaram-se parte do quotidiano das pessoas e das instituiçôes. Muito do que se fazia na escola, por exemplo, já não faz mais sentido, e, se persiste, é justamente porque se esperava que essas coisas sumissem na base do "impacto". O que há, em minha opinião, é um processo de apropriação tecnológica que se dá em dois sentidos. Num primeiro sentido, que eu chamo de "pedagogização acrítica”, o que se faz é distorcer o que seria o "espírito da tecnologia” para continuar-se a fazer as mesmas coisas de sempre passando pelo computador, mas sem que o poder do computador afete de fato o processo.

Para dar um exemplo bobo, eu soube de um projeto numa uma escola de ensino básico em que os alunos tinham que escrever uma carta para a mãe, em homenagem ao dia das mães. As crianças escreveram as cartas à mão 
(para a professora poder ver que erros de ortografia estavam cometendo, sem ajuda do corretor ortográfico do processador de texto), depois foram até o laboratório de informática para digitá-la e ornamenta-la no processador de texto. As cartas foram então impressas pela monitora do laboratório (porque se temia que ensinando as crianças a usar a impressora haveria desperdício de papel) e coladas em um mural no pátio da escola, para serem exibidas na festa para as mães. Eis o resultado: as crianças acharam muito chato ter que digitar uma coisa que já tinham escrito; as mães gostaram da homenagem, mas mais porque estavam desconfiadas de que os filhos não estavam sendo ensinados a usar o computador, do que pela homenagem em si; houve uma briga entre dois alunos, porque um deles zombou do tom (excessivamente?) carinhoso com que o outro se dirigira à mãe, ao que o outro reagiu com violência física. Isso é pedagogização acrítica: dá-se um jeito de inserir o computador numa prática tradicional, usa-se o computador de forma contrária ao seu espírito (para copiar e não para processar, para reproduzir e não para construir, etc.), e com isso distorce-se o que de fato se pretende ensinar (carta para a mãe é um gênero privado que, em geral, se escreve à mão, ou, quando se digita, se envia em forma eletrônica, como um email, por exemplo).

O segundo sentido da apropriação tecnológica eu chamo de "apropriação ascedente". Ela começa com um grupo de pessoas que partilham de um ideal comum ao qual o espírito dos computadores e das redes telemáticas se adapta e que, uma vez incorporado às práticas desse grupo, promove transformaçóes nos modos de pensar, fazer e sentir. Nós vemos isso acontecendo nas grandes "empreitadas digitais" do nosso tempo: Google, 
Facebook, YouTube, Wikipedia são empreendimentos em que as coisas se deram mais ou menos assim, embora, exceto pela Wikipedia, eles tenham, posteriormente, tornando-se negócios que já não são orientados a ideais outros senão o do lucro. Esse tipo de apropriação traz consigo a necessidade de pedagogias colaborativas e voltadas para projetos, a legitimação de várias formas de participação, a fluidez dos objetivos e das lideranças, e, sobretudo, uma abertura para além dos muros da escola (ou do AVA) e a formação orgânica de uma governança coletiva, pela qual todos se responsabilizam pelo processo e pelo produto. Um simples blog ou um grupo de WhatsApp pode ser a "infraestrutura técnica" de um processo como esse. Mas quando pensamos nos outros elementos do processo, fica claro que temos muito a fazer em termos de metodologia, currículo, avaliação, protagonismo, etc. para que esse tipo de movimento se torne possível.

CARACOL: Em que medida você acha que esse movimento se aplica ao contexto brasileiro?

MEKB: Os dois movimentos de apropriação de que falei antes se aplicam, até onde posso ver, à maioria dos países, com diferenças de grau, mas penso que no Brasil temos três fatores específicos que afetam a equação fortemente. $\mathrm{O}$ primeiro é a questáo do acesso. $\mathrm{O}$ segundo, o da formaçáo dos professores e do entorno. O terceiro, o dos currículos e das avaliaçóes.

A questão do acesso é a mais obvia: faltam computadores portáteis, projetores, conexôes rápidas e confiáveis, suporte técnico, gestão ágil na escolha, aquisiçáo, licenciamento e customização de software e assim por diante. Isso é básico e necessário, mas está muito aquém do suficiente. 
Porque há interesses comerciais e políticos envolvidos, e porque comprar máquinas e exibi-las é a forma mais eficaz de "mostrar serviço", esse também é o ponto que os governos (ou donos de escolas privadas) atacam com mais frequência. Aliás, hoje temos o fenômeno dos smarphones, mais de um smartphone por pessoa no Brasil, que mitigou em parte essa carência, embora, claro, um smartphone seja muito limitado em comparação a um computador para o tipo de atividade que se faz na escola. Além disso, o uso de smartphones na sala de aula é proibido por lei em muitos estados.

A questão da formação de professores é muito mais difícil, porque ela não pode ser simplesmente "comprada". Nos anos 1990, quando comecei a me interessar por esse tema, a questão era que os professores não sabiam nem ligar o computador, não entendiam como funcionavam os programas, se confundiam com ícones e convençôes de navegação, não entendiam conceitos como arquivo compactado, DNS, plug-in, etc. Creio que para a grande maioria dos professores que formamos hoje, esse não é mais o problema. Até porque a maior parte deles tem muita familiaridade com computadores, celulares e internet em suas vidas privadas, ficou mais claro que a dificuldade mais grave do professor, pelo menos dos mais jovens, é compatibilizar o papel que a escola formatou para eles com as demandas dos alunos por práticas escolares mais condizentes com as práticas do quotidiano dos jovens. Além disso, é preciso dar conta do currículo, das metas de avaliação, das expectativas dos pais e da carga administrativa e burocrática que faz parte do seu trabalho.

Em países melhor qualificados em educação internacionalmente, em geral, os professores têm muito mais autonomia para compatibilizar esses fatores, 
além de tempo pago e verbas reservadas para criar e estruturar projetos em que as mudanças necessárias vão sendo testadas e aprimoradas. Além disso, naqueles países, são muito menores as carências de formação que sabemos que existe hoje no Brasil, como, por exemplo, professores de línguas estrangeiras que não dominam as línguas que ensinam. Uma formação sólida na sua área de especialidade é fundamental para que o professor possa experimentar com as tecnologias. Senão, o professor vai ficar preso ao livro didático, porque já vem com respostas, aos temas e problemas de sempre, porque ele já sabe como controlar os resultados, ou então, o que eu acho até pior, vai partir para a pedagogização acrítica, vai "aleijar" a tecnologia para que ela não leve a coisa por caminhos em que ele se sente inseguro.

Outra coisa fundamental é que os professores não são envolvidos, em geral, nas escolhas de infraestrutura tecnológica na escola. Ninguém pergunta se ele prefere esse ou aquele tipo de máquina para trabalhar, se ele precisa de mais memória para trabalhar com jogos ou conexão mais rápida para trabalhar com internet, se ele quer plugar o laptop na própria mesa e dar aula de frente para os alunos, ou se quer um PC numa estante junto à lousa para ele dar aula de costas. No caso da $\mathrm{EaD}$, os dilemas são parecidos; em geral, primeiro decide-se a estrutura técnica, o AVA, as partes que são abertas ou fechadas, que tipo de plug-in roda ou náo, que tipo de arquivo pode ser carregado, etc. Depois se espera que o tutor/facilitador e os alunos se adaptem a isso e ponto final.

Finalmente há a questão dos currículos, que são bastante engessados e centrados em conteúdos, em lugar de habilidades e experiências, e que esperam que a interdisciplinaridade apareça do nada, por esforço individual 
de professores que, e geral, não foram formados para isso. $\mathrm{O}$ paradigma das redes vem casado com o da interdisciplinaridade. Quem quer entender um gráfico em língua estrangeira publicado na internet precisa entender um mínimo de estatística para saber criticar as conclusóes de que apresenta o gráfico, precisa saber instalar o plug-in que permite interagir com as variáveis do gráfico, e assim por diante. Há também o problema dos testes padronizados e do próprio vestibular que são pensados para um aluno que usa computador, mas não depende de computador. Essa é uma questão mais complexa, mas me preocupa que queiramos selecionar com papel e caneta as pessoas mais capazes para fazer avançar os mundos da ciência e do trabalho em que a dependência de computadores não só é um fato como uma tendência sempre crescente. Náo seria hora de começarmos a admitir que estamos todos virando ciborgues mais rápido do que previam os filmes de ficção científica, e procurar testar o que um conjunto pessoa + computador é capaz de fazer? Como esses testes têm grande influência em como se planeja o ensino, esse tipo de discussão talvez pudesse incentivar um tipo de apropriação tecnológica mais progressista.

CARACOL: Podemos afirmar que o perfil do professor no século XXI já mudou? E o perfil do aluno, já é outro? Por quê?

MEKB: Creio que já abordei essa questão indiretamente nas perguntas anteriores, mas eu diria que estamos vivendo uma espécie de esquizofrenia em que tanto professores como alunos têm perfis duplos, um para a escola e outro para a vida. E penso que em ambos os casos a culpa não é deles. Nós 
tendemos a nos esquecer de que a escola é uma tecnologia. Como tal, ela tem uma certa inércia, ela restringe certos comportamentos e impulsiona outros.

Nós sabemos, por exemplo, que copiar da lousa é uma coisa que existe na escola, mas aparentemente só mesmo na escola. Quando um aluno pega o celular e tira foto da lousa e um professor reclama disso, está claro que ou o professor acredita que copiar gera aprendizagem, ou ele está contando o tempo da cópia como tempo de aula. A pergunta que se faz é: o professor tem um "perfil analógico" e o aluno um "perfil digital”? Ou é o arranjo tecnológico da escola, onde quantidade de trabalho/aprendizagem é medida em forma de tempo e onde o aluno só tem acesso ao texto depois que o professor o transferiu (da mente, ou de um livro) para a lousa, que os levou a agir assim?

Claro, nós sabemos que os jovens hoje têm um perfil cognitivo e comportamental diferente. Eles não toleram bem atividades exclusivas de longa duração (como uma aula de cinquenta minutos) porque estão habituados à multiplicidade de atividades ao mesmo tempo, ao acesso a múltiplos espaços virtuais e interlocutores dentro de um mesmo espaço físico, a registrar automaticamente em lugar de copiar manualmente, a encontrar múltiplas representaçóes da mesma ideia, em múltiplas linguagens e mídias, em vez de contentarem-se apenas com o texto escrito e, assim por diante. Porém nós temos muitos professores jovens, ou seja, pessoas que foram socializadas nessas mesmas dinâmicas e, em princípio, teriam o mesmo perfil. Eu considero simplista acharmos que os professores mais velhos têm outro perfil porque são mais velhos. Penso que os mais jovens 
talvez sofram mais do que os mais velhos porque a escola como tecnologia os condiciona, até certo ponto, a portarem-se como os mais velhos. Já os mais velhos que optaram por não apropriarem-se do digital, ou foram impedidos de fazê-lo, sofrem por terem que sustentar os modos de agir por necessidade, e não por opção.

CARACOL: Que avanços teórico-metodológicos são necessários para uma integração mais eficaz das TIC na educação?

MEKв: Eu vejo como cada vez mais relevantes as pedagogias críticas, especialmente que elas incorporem as tecnologias em si como signos, como objetos de análise; da mesma forma, que se use essas pedagogias como meio de constituir objetos de análise crítica (por exemplo, analisar a "relevância" de certos temas ou vozes por meio de buscas no Google). Da mesma forma, são cada vez mais relevantes as pedagogias colaborativas e de projetos, porque elas dão sustentação ao que chamo de apropriaçôes ascendentes.

Do ponto de vista teórico, eu penso que os conceitos de letramentos digitais, novos letramentos, multiletramentos e transletramentos têm ajudado tanto na apropriação do tema da tecnologia pelos pesquisadores e professores de Letras, Linguística e Literatura, quanto na intervenção dessas áreas do saber nos debates sociais sobre tecnologia e educação e mesmo sobre inclusão digital. Isso porque são conceitos que afrontam a ideia de impacto, assim como chamam a atenção para os processos de apropriação, para a noção de que o que conta não é só o que o computador faz, mas o que se faz com ele. 
Pensando a longo prazo, creio que tenhamos que avançar fortemente na pesquisa sobre pós-humanismo, que é um dos temas que estudo atualmente. Está ficando cada vez mais claro que o modelo liberal do sujeito autônomo, consciente e autodirigido não dá conta de explicar o modo como nós agimos, pensamos e sentimos desde que nos tornamos seres hiperconectados, por um lado potencializados, e por outro tornados dependentes, de computadores e redes digitais. Nós estamos começando a ter ideia das repercussóes disso nos nossos usos de linguagem. Mas há implicaçóes éticas, políticas, afetivas, etc. que precisam ser discutidas para que possamos repensar a educação também nesse sentido.

CARACOl: Considerando esse cenário, que demandas ou desafios se apresentam para as instituiçôes de ensino superior formadoras de professores?

MEKв: O grande desafio das IES, na minha opinião, é transformarem-se de modo a fazerem o que pregam. É claro que precisamos de boas disciplinas de graduação, bons programas de estágio, e boas linhas de pesquisa em pós-graduação votadas para essa problemática de que estamos falando. Mas como docente, sinto que nós dizemos aos professores em formação para fazerem algo que nós mesmos não fazemos, e pelos mesmos motivos, ou seja, porque as IES como tecnologias condicionam nossas açóes nessa direção. Nós também temos que cumprir currículos que por vezes nos aprisionam, nós também poucas vezes participamos, ou queremos participar, das decisóes sobre infraestrutura técnica, etc. Por outro lado, o professor formador tem mais autonomia, na maior parte dos casos, do que o professor em formaçáo terá quando formado. É importante usar essa autonomia para dar o exemplo. 
Mas igualmente importante é proporcionar aquele tipo de formação sólida na área de especialidade, porque, ao final do dia, é a confiança em sua competência central que vai fazer esse futuro professor poder arriscar, se apropriar da tecnologia num sentido transformador.

CARACol: Pensando na produção de materiais e conteúdos digitais para o ensino de línguas na escola básica, no seu modo de ver, como os pesquisadores podem contribuir?

MEкв: Muitos pesquisadores contribuem construindo protótipos e oferecendo parâmetros e diretrizes para materiais que aproveitem a potência do digital, em vez de deformá-lo para caber nos velhos moldes. Há ainda cursos de extensão em que professores têm oportunidade de desenvolver materiais de forma direcionada por pesquisadores e suas equipes. Também temos pesquisadores atuando em equipes que definem os parâmetros para materiais didáticos a serem adquiridos pelo governo, e que pesquisam os efeitos desses materiais em uso. Finalmente, existem livros e artigos acadêmicos em que se discute e divulga novas possibilidades de produção de materiais, ou se fundamenta teoricamente critérios de escolha e rejeição de materiais comerciais. Creio que essas sejam as formas mais eficazes de contribuição direta dos pesquisadores no momento, e, claro, seria muito importante ampliar o acesso a elas para todos os pontos do país via $\mathrm{EaD}$.

De forma mais indireta, acredito que a universidade é o lugar de onde devem partir experiências interdisciplinares e interculturais online, que paulatinamente possam subsidiar a produção de atividades e materiais desse tipo na escola. Hoje temos condiçóes de colocar nossos alunos em contato 
com falantes de outras línguas do mundo todo com grande facilidade. Mas será que saberíamos ensinar os alunos a sustentar essas interaçóes interculturais fora da sala de aula? Temos alunos brasileiros que pode ensinar matemática para um aluno argentino e aprender química com ele, mas não temos problemas que envolvam matemática e química de tal modo a fomentar o diálogo e a alternância de código entre eles.

CARACOL: Quais seriam os principais desafios e perspectivas para a formação de professores de línguas com respeito às estratégias de aprendizagem e de ensino no cenário tecnológico?

MEKB: Penso que os desafios são também oportunidades, e destacaria dois deles: transmidialidade, colaboratividade.

A transmidialidade diz respeito ao modo como os sentidos sociais são hoje constituídos no atravessamento de diferentes mídias e linguagens. Os melhores exemplos que temos no momento vêm do campo do entretenimento, onde produtos como Matrix ou Harry Poter estabeleceram um novo paradigma pelo qual a narrativa encontra-se distribuída (filme, livro, videogame, série, atração no parque temático, $\mathrm{HQ}$, etc) e permite diferentes níveis de interpretação e diferentes percursos de sentido conforme as escolhas e experiências individuais do público. As pessoas que hoje se divertem assim, certamente desejarão/necessitarão aprender assim também. O desafio para o professor é orquestrar essa rede, projetar esses percursos, orientar certas escolhas e sequências de temas e formato a certos objetivos e níveis da aprendizagem, e, sobretudo, encontrar formas de legitimar e 
avaliar essa heterogeneidade de experiências. Os MOOCs são, talvez, a semente mais adiantada disso. A participação de professores em formação em MOOCs talvez seja uma boa forma de começar a expô-los a essa necessidade.

A colaboratividade está diretamente ligada ao desejo de participação do consumidor no processo de produção daquilo que ele consome. Novamente isso fica mais claro no campo da indústria cultural, onde emerge a figural do "produsuário", isto é, o usuário de um serviço/conteúdo que também produz, em parte esse serviço/conteúdo. Muitas séries de TV, por exemplo, mantém espaços de discussão online onde os fẫs expôem suas opinióes, debatem rumos da história, levantam hipóteses, etc., e, muitas vezes, os produtores acolhem essas ideias e as incorporam na série, ou fornecem "pistas" nos episódios que sustentam ou refutam as hipóteses dos fãs. A Wikipedia também é um exemplo de produsagem, já que as pessoas que a consultam também podem colaborar, expandindo os verbetes, ou mesmo participando como "guardiôes" que verificam avisos de que as páginas foram vandalizadas e restauram a versão original quando necessário.

Aqui o desafio do professor é não só ter uma aula mais participativa, em que ele fala menos e os alunos falam mais, com ele, entre si, e com pessoas online que possam contribuir, mas também envolver os alunos na produção dos materiais, no desenho das atividades, nas avaliaçóes, etc. Como o produtor da série, a ideia é que o professor estabeleça um diálogo e direcione o percurso do ensino nessa "dança" com as hipóteses, desejos, dúvidas, etc. dos alunos. Claro que o desafio do professor é maior do que o 
do produtor, porque não se trata de produzir o que o aluno quer consumir, simplesmente, mas de leva-lo a querer o que ele precisa saber.

CARACOL: Pensando nas diversas competências, como se definiria a do professor de línguas em relação à tecnologia? Quais seriam os saberes necessários para esse professor no contexto da escola básica? Como os cursos de formação de professores podem contribuir?

MEKB: Penso que para além das competências mais óbvias como saber a língua que ensina, saber lidar minimamente com os equipamentos digitais que vai usar, saber estruturar um conjunto de atividades em função de um objetivo didático e avaliar se tal objetivo foi alcançado ou não, o professor necessita de algumas competências menos óbvias, e, por isso mesmo, menos abordadas em cursos de formação.

A primeira competência seria ética, ou seja, teríamos que formar um professor capaz de fazer e responder certas perguntas como "A quem isso beneficia?", "Por que tal recurso é gratuito, se não é público?", "Esse artefato tem uma interface centrada no usuário? Consigo torna-la centrada em aprendizagem?", "Até onde eu e o meu aluno somos capazes de entender/ conhecer as repercussóes das açóes que realizamos nele ou por meio dele?", e, assim por diante. Isso é fundamental, porque a principal característica das tecnologias atuais é distribuir as açóes e o sentido das açóes, e porque tecnologias nunca são neutras, elas são política feita por outros meios.

Uma segunda competência, que eu não sei bem como nomear, seria a necessária resistir à pedagogizaçáo acrítica e fomentar as apropriaçóes ascendentes. Isso tem a ver com o professor se perguntar: "Como a ação está 
distribuída nessa atividade?", "Quem está agindo e o que está fazendo cada um?”. Sempre que aluno e computador ou professor e computador estiverem fazendo algo que nenhum deles poderia fazer pelo outro, ou sem o outro, em princípio se está caminhando no sentido da apropriação. Sempre que o computador estiver fazendo um papel falso, apenas para dizer-se que ele foi usado, em princípio isso é pedagogizaçao acrítica. A dificuldade envolvida aí é o nosso preconceito de que apenas os humanos agem, apenas eles são sujeitos. É preciso “outorgar", mesmo que temporariamente, o status de agente ao computador, e entender com profundidade o que ele está fazendo, ou o que estão fazendo por meio dele.

Penso que a contribuição dos cursos de formação é habituar o professor em formação com essas perguntas, não apenas em relação ao planejamento e execução de atividades didáticas, mas, sobretudo em relação à sua própria vida, seus usos do digital no quotidiano. Penso que isso é algo análogo a acostumar um licenciando em espanhol ou inglês a, quando lê ou ouve um texto na língua-alvo, perguntar-se: "Mas por que essa voz passiva ou esse ergativo nessa frase? Porque se usou a palavra $\mathrm{X}$ e não os sinônimos y ou z". Enfim, se a verdadeira interpretação vai além da palavra e em direção aos discursos, também um uso de tecnologia que possamos chamar de educacional tem que ir além dos procedimentos, de onde clicar primeiro, etc., em direção ao design num sentido amplo, ao modo como o artefato nos usa quando usamos o artefato. 